\title{
Thick CrN/NbN Multilayer Coating Deposited by Cathodic Arc Technique
}

\author{
Juliano Avelar Araujo ${ }^{a}$, Roberto Martins Souza ${ }^{b}$, Nelson Batista de Lima ${ }^{c}$, André Paulo Tschiptschin ${ }^{a, d *}$ \\ ${ }^{a}$ Metallurgical and Materials Engineering Department, University of São Paulo - USP, Av. Prof. Mello \\ Moraes, 2463, ZIP 05508-030, São Paulo, SP, Brazil \\ ${ }^{b}$ Mechanical Engineering Department, University of São Paulo - USP, Av. Prof. Mello Moraes, 2231, \\ ZIP 05508-030, São Paulo, SP, Brazil \\ ${ }^{c}$ Department of Materials Characterization, Nuclear and Energy Research Institute - IPEN, Av. Prof. \\ Lineu Prestes, 2242, CEP 05508-900, São Paulo, SP, Brazil \\ ${ }^{d}$ Brazilian Nanotechnology National Laboratory - LNNano, Brazilian National Center of Research in \\ Energy and Materials - CNPEM, Rua Giuseppe Maximo Scolfaro, 10000, CEP 13083-100, Campinas, \\ SP, Brazil
}

Received: April 10, 2016; Revised: October 25, 2016; Accepted: November 21, 2016

\begin{abstract}
The production of tribological nanoscale multilayer $\mathrm{CrN} / \mathrm{NbN}$ coatings up to $6 \mu \mathrm{m}$ thick by Sputtering/HIPIMS has been reported in literature. However, high demanding applications, such as internal combustion engine parts, need thicker coatings $(>30 \mu \mathrm{m})$. The production of such parts by sputtering would be economically restrictive due to low deposition rates. In this work, nanoscale multilayer $\mathrm{CrN} / \mathrm{NbN}$ coatings were produced in a high-deposition rate, industrial-size, Cathodic Arc Physical Vapor Deposition (ARC-PVD) chamber, containing three cathodes in alternate positions $(\mathrm{Cr} /$ $\mathrm{Nb} / \mathrm{Cr}$ ). Four $30 \mu \mathrm{m}$ thick $\mathrm{NbN} / \mathrm{CrN}$ multilayer coatings with different periodicities $(20,10,7.5$ and 4 $\mathrm{nm}$ ) were produced. The coatings were characterized by X-Ray Diffraction (XRD) and Transmission Electron Microscopy (TEM). The multilayer coating system was composed of alternate cubic rocksalt $\mathrm{CrN}$ and $\mathrm{NbN}$ layers, coherently strained due to lattice mismatch. The film grew with columnar morphology through the entire stratified structure. The periodicities adopted were maintained throughout the entire coating. The $20 \mathrm{~nm}$ periodicity coating showed separate $\mathrm{NbN}$ and $\mathrm{CrN}$ peaks in the XRD patterns, while for the lower periodicity $(\leq 10 \mathrm{~nm})$ coatings, just one intermediate lattice (d-spacing) was detected. An almost linear increase of hardness with decreasing bilayer period indicates that interfacial effects can dominate the hardening mechanisms.
\end{abstract}

Keywords: $\mathrm{NbN} / \mathrm{CrN}$, Multilayer Coatings, Cathodic Arc, Nanostructure

\section{Introduction}

The $\mathrm{CrN}$ is a classic coating system, which is technologically relevant since the early $1980{ }^{1-5}$. The high hardness and lower friction coefficient, when compared to other piston ring system coatings ${ }^{2,6,7}$, has drawn engineer's attention to the use of this kind of coating for internal combustion engine components. Currently, it is applied in large scale for piston rings ${ }^{2,5}$. While typical applications may not require the PVD coating thickness to be above $6 \mu \mathrm{m}^{5}$, it frequently needs to be on the order of $30 \mu \mathrm{m}$ when the PVD layer is deposited onto a combustion engine component ${ }^{5-7}$. Such high thickness is mandatory when considering the highly demanding environment of internal combustion engines, which is associated to high wear rates ${ }^{8}$. Furthermore, the increasing combustion pressures and the reduced lubrication oil availability found in new generation engines require additional toughness and wear resistance to avoid damage of the parts.

In recent years, multilayer $\mathrm{CrN} / \mathrm{NbN}$ coatings have attracted Engineer's attention, since the niobium nitride

\footnotetext{
* e-mail: antschip@usp.br
}

component $(\mathrm{NbN})$ stands out for its chemical stability ${ }^{8}$ and the chromium nitride $(\mathrm{CrN})$ is a hard and inert coating component ${ }^{2,3}$, offering the temperature resistance required for working in the combustion chamber environment. $\mathrm{NbN}$ / $\mathrm{CrN}$ nanostructured multilayer coating combines high hardness with chemical stability and toughness. Besides that, Munz et al. ${ }^{9}$ have reported a superior wear resistance of $\mathrm{CrN} / \mathrm{NbN}$ multilayer coatings over single layer coatings and electrodeposited chromium. Most of $\mathrm{CrN} / \mathrm{NbN}$ coatings studied were produced by sputtering process, with or without an interlayer produced by cathodic arc evaporation ${ }^{10-14}$. In a few cases $^{15}$, the coatings were entirely produced by the cathodic arc technique, as in this work. Many $\mathrm{CrN} / \mathrm{NbN}$ PVD coatings described in the literature are up to $6 \mu \mathrm{m}$ thick, which makes them inappropriate for applications that require long-term high wear resistance, such as internal combustion engine parts. The issues in achieving larger thicknesses using sputtering include the difficulty in keeping the multilayer periodicity through the entire coating, due to target poisoning. Many authors have studied the relationship between structure and mechanical properties of different PVD sputtered multilayer coatings with typical thickness 
between $2-5 \mu \mathrm{m}$, relating such properties to the periodicity $(\Lambda)$ and the interface morphology $y^{12,16-18}$

Hovsepian et al. ${ }^{19-21}$, Munz et al. ${ }^{9,12}$ and Tomlinson et $a l .{ }^{14}$ have reported the characterization of multilayer $\mathrm{CrN} /$ $\mathrm{NbN}$ coatings, particularly pointing out the advantages of using arc bond sputtering (ABS). The results showed that the position of $\mathrm{CrN}$ and $\mathrm{NbN} \mathrm{X}$-ray diffraction peaks represented the weighted mean of the individual reflections of the $\mathrm{CrN}$ and $\mathrm{NbN}$ phases. According to the authors, the occurrence of satellite peaks demonstrated the superlattice nature of the coating structure. Additionally, Hovsepian et al..$^{22}$ produced $\mathrm{CrN} / \mathrm{NbN}$ by three different PVD techniques (ABS, UBM and ARC) and showed that, despite the low bias voltage of ARC process, there is an increase in ion energy up to $300 \mathrm{eV}$. This value resulted in an increased adatom mobility, when compared to $120 \mathrm{eV}$ for UBM, which suppresses interface roughness effects and may produce a smoother interface between individual $\mathrm{CrN}$ or $\mathrm{NbN}$ layers. $\mathrm{CrN} / \mathrm{NbN}$ deposited by ARC showed the lowest friction coefficient and highest wear resistance, when compared to $\mathrm{CrN} / \mathrm{NbN}$ produced by sputtering processes.

Lewis et al. ${ }^{23}$ grew $\mathrm{CrN} / \mathrm{NbN}$ by UBM in different bias voltages and found up to $14 \%$ reduction in periodicity throughout the multilayer in coatings $1.4 \mu \mathrm{m}$ thick. The reduction was consistent for $3.0 \mu \mathrm{m}$ thick coatings as well. The periodicity reduction was justified by the increase of target poisoning with time.

Wang et al. ${ }^{24,25}$ studied the corrosion and wear resistance of $\mathrm{NbN} / \mathrm{CrN}$ coatings produced by ABS. They showed that the coating must be substantially thicker than the size of the macroparticles causing wear, in order to mitigate their effects on the $\mathrm{NbN} / \mathrm{CrN}$ coating performance.

Pecchio $^{15}$, Bemporad ${ }^{13}$, Ceschini $^{26}$, Martini $^{27}$ and Pilone ${ }^{28}$ have studied $\mathrm{NbN} / \mathrm{CrN}$ coatings entirely produced by arc processes. These coatings were produced using the switch cathodic arc evaporation technique, which is characterized by alternate triggering of the $\mathrm{Cr}$ or $\mathrm{Nb}$ cathodes. These coatings showed better wear performance than $\mathrm{CrN}$ single-material coatings produced by the same process.

It is important to notice that the research works mentioned above were centered on coatings with thickness lower than $6 \mu \mathrm{m}$. In terms of deposition processes, cathodic ARC has industrial interest due to its high deposition rate when compared to sputtering. The later would be economically restrictive when one compares the deposition rate of Sputtering/HIPIMS $(\sim 1.2 \mu \mathrm{m} / \mathrm{hr})^{23,29}$ with ARC $(\sim 3.0 \mu \mathrm{m} / \mathrm{hr})^{13}$.

This work explored and found features never presented before. One example is the high coating thickness - in the order of $30 \mu \mathrm{m}$, since coatings with such thickness were reported only in a previous work by the authors ${ }^{33}$. In addition to the technological benefit, extending service life of components, the thick coatings in this work allowed exploring some features of the cathodic arc technique such as the evolution of the coating structure during the deposition process. In this case, the results confirmed the trend for a particular preferential crystallographic orientation depending on periodicity, but, different from sputtered coatings found in the literature, the deposition conditions remained similar with deposition time, ensuring that a consistent value of periodicity was obtained along the entire coating thickness of each deposition process. Another important point of the cathodic arc process is the presence of macroparticles, which have caused local changes in the structure. However, the amount of macro particles, and the associated loss of parallelism of the layers with the coating/substrate interface, has not prevented the use of characterization techniques such as kinematic X-ray diffraction to calculate periodicity based on the position of satellite peaks.

In this work, gas nitrided martensitic stainless steels coupons were PVD-coated using the cathodic arc process. The $30 \mu \mathrm{m}$-thick $\mathrm{NbN} / \mathrm{CrN}$ multilayer coatings were deposited with various periodicities but keeping the same periodicity along the entire coating thickness. The aim of the investigation was to characterize the microstructure, periodicity along all coating thickness and the relationships between microstructure and hardness for such thickness values.

\section{Experimental Procedure}

$\mathrm{NbN}$-only and $\mathrm{CrN}$-only coatings, as well as $\mathrm{NbN} / \mathrm{CrN}$ multilayer coatings with different periodicities ( $\Lambda$ varying from 4 to 20 nanometers), were deposited onto gas nitrided martensitic stainless steel (AISI 440B) coupons.

Substrate Preparation and Cleaning - The steel strip was ground and diamond polished, keeping the surface roughness before deposition below $\mathrm{Rz}=0.5 \mu \mathrm{m}$. Before being placed in the deposition chamber, the coupons were chemically cleaned in two different stages. The first stage consisted in the use of a degreasing agent, Renoclean ${ }^{\circledR} 237$, for removal of inorganic and organic residue, while the second stage consisted in ultrasonic rinsing with deionized water.

Coating Deposition - Depositions were conducted in an industrial cathodic arc physical vapor deposition equipment (Hauzer Techno Coating Europe B.V., model HTC750). Figure 1 shows the schematic drawing of the cross section of the equipment displaying the cathode positions. The chamber has three rectangular cathodes (working area of $1200 \mathrm{~cm}^{2}$ ), each one capable of working independently and having its own power supply.

The multilayer periodicity was controlled by varying the rotating speed of the table and consequently the time that the specimens pass in front of each target without shield/ shutter. The specimens were placed facing the targets in a two-fold rotating table, at a distance of $10 \mathrm{~cm}$ from the substrate. The table rotated around the vertical axle of the reactor and each specimen rotated around its own center, to ensure a homogeneous deposition on top of the entire specimen. The rotating speeds were increased 2, 3 and 5 


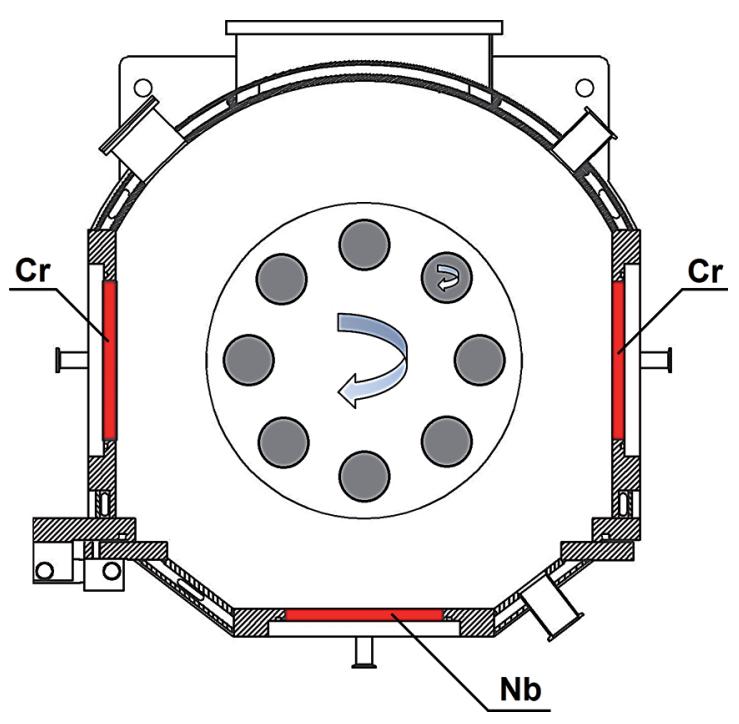

Figure 1: Schematic drawing of the cross section of the HTC-750 coating chamber, showing the target/cathodes positions.

times, leading to the formation of coatings with periodicities of $20 \mathrm{~nm}, 10 \mathrm{~nm}, 7.5 \mathrm{~nm}$ and $4 \mathrm{~nm}$.

The substrate was heated to $400{ }^{\circ} \mathrm{C}$, a floating bias voltage was applied and the maximum output was $120 \mathrm{~W} /$ $\mathrm{cm}^{2}$ for each cathode. Before the deposition of the coatings, the substrates were ion cleaned with $\mathrm{Cr}$ targets switched on (metal ion cleaning) in Ar atmosphere.

The average deposition rate was $3 \mu \mathrm{m} / \mathrm{h}$, as detailed below, and the total thickness of the multilayer coatings was $30 \mu \mathrm{m}$, in all cases.

The deposition process consisted of three stages:

1. Ion cleaning using a bias voltage of $-900 \mathrm{~V}$.

2. Deposition of a metallic chromium bonding layer under argon atmosphere, with total pressure lower than $10^{-3}$ mbar and using a substrate bias voltage of $-20 \mathrm{~V}$.

3. Deposition of multilayer coatings by simultaneous operation of all three targets. During the whole deposition process, the total pressure was kept at $3 \times 10^{-3}$ mbar and the ratio between argon and nitrogen was kept at 0.25 . The electric current applied to niobium and chromium targets was balanced aiming an atomic ratio of $\mathrm{Nb} / \mathrm{Cr}=0.8$. The total time for effective deposition was 9.5 hours.

The superlattice periodicity is controlled by the power dissipated on the targets, the partial pressure of the reactive gas, the bias voltage applied to the substrate and the primary rotation speed of the turntable.

After deposition, cross sections of the coatings were cut with a diamond disk in the preparation for observation, mounted in Bakelite, ground with silicon carbide paper (\#120,\#320 and \#1200) and polished using diamond paste (3 $\mu \mathrm{m}$ and $1 \mu \mathrm{m})$.
Measurements of the total thickness of the coatings were conducted using a FEI Quanta 600 - FEG scanning electron microscope. Additionally, qualitative and semiquantitative chemical composition assessments of all the coatings were carried out using energy-dispersive X-ray spectroscopy (EDS). The crystallographic structures of the multilayer coatings were determined by X-ray diffraction using a Multiflex Rigaku diffractometer. A configuration of Bragg-Brentano $\theta-2 \theta$, copper $\mathrm{K} \alpha$ radiation (1.5418 $\AA$ ) and $2 \theta$ angles varying from $20^{\circ}$ to $120^{\circ}$ with an interval of $0.02^{\circ}$ and 2 seconds of integration time per point was used.

The coatings were also characterized by Transmission Electron Microscopy (TEM) for quantitative analysis of the nanostructured multilayer constituents and assessment of their relative thicknesses and diameter of polycrystalline columns. High Resolution Transmission Electron Microscopy (HRTEM) was used to assess a qualitative evaluation of the interfaces between the sub-layers. For this purpose, thin foils were prepared using an FEI Helios 660 Focused Ion Beam (FIB) scanning electron microscope. In order to carry out the TEM analysis across the $30 \mu \mathrm{m}$ thick coatings, it was used a $200 \mathrm{kV}$ TEM Philips CM20 microscope equipped with an EDS Voyager Noran analyzer (high purity Ge detector and ultra-thin window - UTW). The high resolution images were acquired with a $300 \mathrm{kV}$ HRTEM JEOL 3010. The electron diffraction analysis was conducted following the procedure published by Zuo et al. ${ }^{31}$ and provided information about the crystal structure of individual sub-layers ( $\mathrm{NbN}$ and $\mathrm{CrN})$, the orientation of the (hkl) planes and the preferential direction of crystal growth.

A Micro Combi Tester with instrumented indentation system (maximum normal loads up to $500 \mathrm{mN}$ ) and a Hysitron TI950 (30 s load/unload and maximum normal load up to 10 $\mathrm{mN}$ ) were used to assess the coating microhardness, according to the ISO standard 14577-4 - Edition 2007. The hardness measurements were conducted on the polished coating cross section. The instrumented microindentation results presented in this work are an average of five measurements. The number of nanoindentations in each sample was significantly higher (over 200) and aimed at measuring hardness along the entire coating thickness.

\section{Results and Discussion}

\subsection{Microstructure of single layer coatings ( $\mathrm{NbN}$ or $(r N)$}

The structure of individual $\mathrm{NbN}$ and $\mathrm{CrN}$ coatings depends mainly on the nitrogen partial pressure, the bias voltage and the total pressure. Transition metals nitrides exist in different allotropic forms with different stoichiometries. For instance, nitrides composed of $\mathrm{Nb}$ and $\mathrm{N}$ can present the following chemical compositions and crystalline structures: 
$\beta-\mathrm{Nb}_{2} \mathrm{~N}$ (hexagonal), $\gamma-\mathrm{Nb}_{4} \mathrm{~N}_{3}$ (tetragonal), $\delta-\mathrm{NbN}$ (facecentered cubic), $\delta$ '- $\mathrm{NbN}$ (hexagonal), $\varepsilon-\mathrm{NbN}$ (hexagonal), $\eta-\mathrm{NbN}$ (hexagonal), and $\alpha-\mathrm{Nb}(\mathrm{N})$ a solid solution formed by metallic $\mathrm{Nb}$ containing solubilized $\mathrm{N}^{11}$. Additionally, nitrides composed of $\mathrm{Cr}$ and $\mathrm{N}$ can appear as: $\mathrm{CrN}$ (face-centered cubic) and $\mathrm{Cr}_{2} \mathrm{~N}$ (hexagonal) $)^{5}$.

Chromium-based (chromium, $\mathrm{CrN}, \mathrm{CrC}$ and $\mathrm{Cr}-\mathrm{C}-\mathrm{N}$ ) hard coatings produced by $\mathrm{PVD}$ have been used successfully in tribological systems where corrosion, oxidation and intense wear are expected. These coatings came out as replacements for electroplated hard chromium in some applications; fcc-CrN coated piston rimgs, have been used successfully in heavy internal combustion engines. The aim of combining chromium with niobium as the chemically stable metal is to enhance the corrosion resistance of the coating and to increase hardness values to $40 \mathrm{GPa}$, by utilizing the superlattice effect ${ }^{20}$. A multilayer coating containing alternate layers of two isostructural phases ( $\mathrm{fcc}-\delta-\mathrm{NbN}$ and fcc - $\mathrm{CrN}$ ) with a small difference in lattice parameter, can give rise to coherency strains/stresses responsible for the strong hardening. Accordingly, $\mathrm{NbN} / \mathrm{CrN}$ depositions were made with settings chosen to properly obtain $\delta$-NbN (face-centered cubic) and $\mathrm{CrN}$ (face-centered cubic) nitrides.

Given that the energy of formation of fcc $\delta-\mathrm{NbN}\left(\Delta \mathrm{H}^{298}\right.$ $=56,8 \mathrm{Kcal} / \mathrm{mol})$ and fcc $\mathrm{CrN}\left(\Delta \mathrm{H}^{298}=29,8 \mathrm{Kcal} / \mathrm{mol}\right)$ differ significantly, adjustment of the deposition parameters of the cathodic arc process is mandatory in order to allow the formation of a multilayer coating constituted only by the two fcc phases, $\delta-\mathrm{NbN}$ and $\mathrm{CrN}$. After optimization of the deposition parameters, individual $\mathrm{NbN}$ and $\mathrm{CrN}$ coatings were produced and analyzed by X-ray diffraction in the $\theta-2 \theta$ geometry, resulting in the X-ray diffraction patterns shown in Figure 2.

Figure 2 shows that both $\mathrm{NbN}$ and $\mathrm{CrN}$ phases have a face centered cubic structure with a (200) preferred orientation. The d-spacings are the same as those indicated on ICDD cards \#38-1155 and \#11-65, respectively, giving lattice parameters of $0.439 \mathrm{~nm}$ for $\mathrm{NbN}$ and $0.415 \mathrm{~nm}$ for $\mathrm{CrN}$, thus producing a difference around $5.5 \%$ between the two parameters. These parameters also suggest that there is no nitrogen excess in the coating structures ${ }^{32}$ and that no significant peak shifts due to coating residual stresses were observed in these cases. The additional lines, visible in the diffraction patterns of $\mathrm{NbN}$ refer to $\mathrm{Nb}$ droplets. The X-ray diffraction patterns in Figure 2 were considered "standards" for individual $\mathrm{NbN}$ and $\mathrm{CrN}$ lines that could be used in comparison with those obtained with the multilayer diffraction pattern.

\subsection{Microstructure of the multilayer coating}

Figure 3 shows a low-magnification photograph of the surface of a $4 \mathrm{~nm}$ periodicity coating. The ARC coating process leads to the formation of a significant amount of droplets on the top of the coated surfaces. The use of these

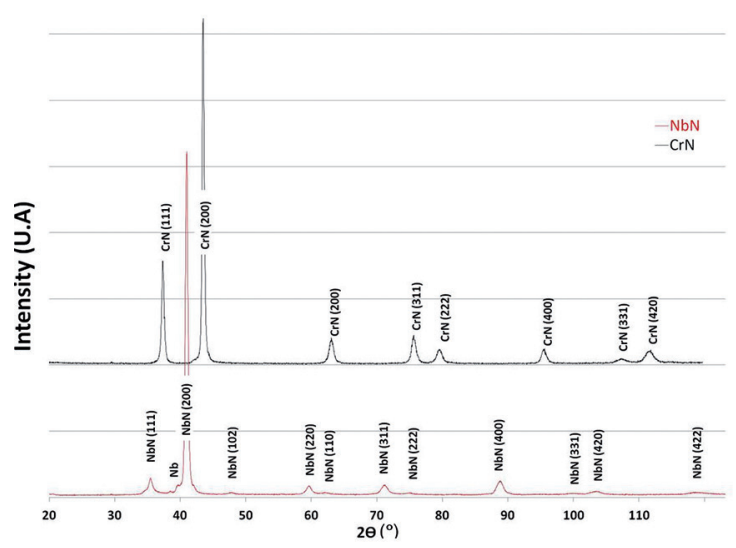

Figure 2: X-ray diffraction patterns of $\mathrm{NbN}$ and $\mathrm{CrN}$ coatings, containing information about the phases and crystallographic planes.

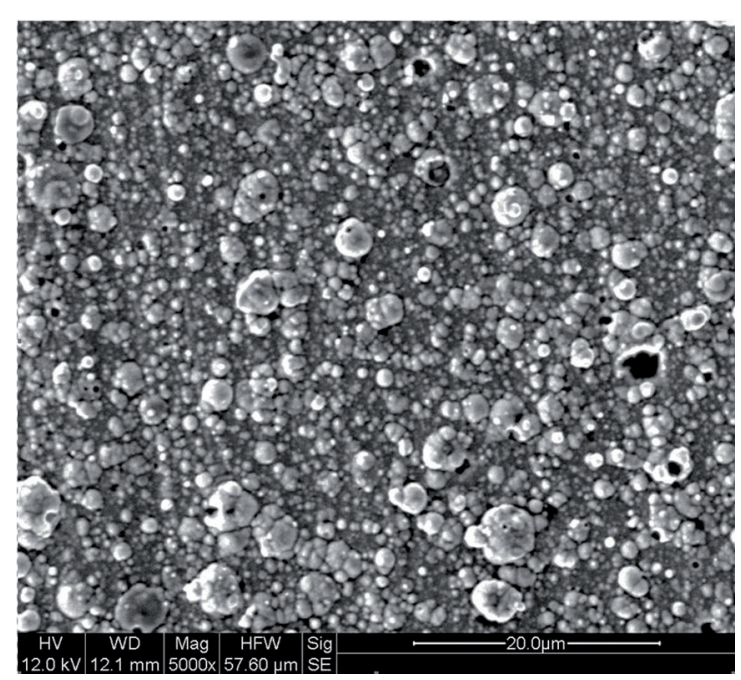

Figure 3: Observation of the coating surface of a $4 \mathrm{~nm}$ periodicity coating at low magnification. SEM (SE image).

coatings for tribological applications requires grinding and polishing after deposition. These macroparticles are present during the entire deposition and they can also interfere with the growth of the nanoscale multilayer coating. This was not the case in this work, as detailed later.

Figure 4 shows the $\mathrm{Cr}$ bonding layer, with an average thickness of $1 \mu \mathrm{m}$, and its columnar structure. Figure 4 provides preliminary evidence that the $\mathrm{NbN} / \mathrm{CrN}$ structure is constituted of uniform and well-spaced alternate layers of $\mathrm{NbN}$ (light) and $\mathrm{CrN}$ (dark). Figure 4 also indicates a dark layer below the chromium layer, most probably formed due to ion etching and chromium diffusion.

Figure 5 shows the $\theta-2 \theta \mathrm{X}$-ray diffraction patterns for all four $\mathrm{NbN} / \mathrm{CrN}$ multilayer coatings with different periodicities.

For the $20 \mathrm{~nm}$ modulated (periodicity) $\mathrm{NbN} / \mathrm{CrN}$ coating, it is possible to identify peaks related to $\mathrm{NbN}$ and $\mathrm{CrN}$. These peaks are displaced with respect to the correspondent positions of the individual peaks of $\mathrm{NbN}$ and $\mathrm{CrN}$ in Figure 2. 


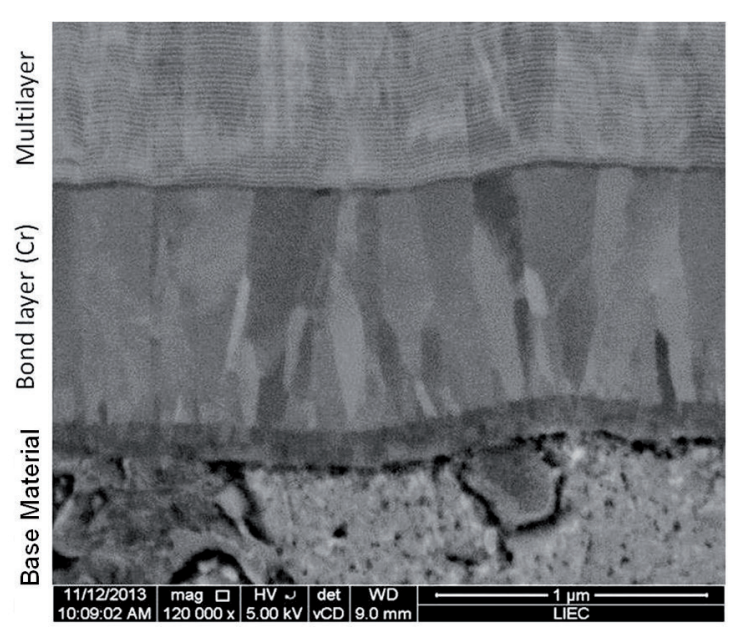

Figure 4: SEM - vCD (low voltage high contrast detector). Detail showing the base material, the chromium bonding layer and the $\mathrm{NbN} / \mathrm{CrN}$ multilayer coating.

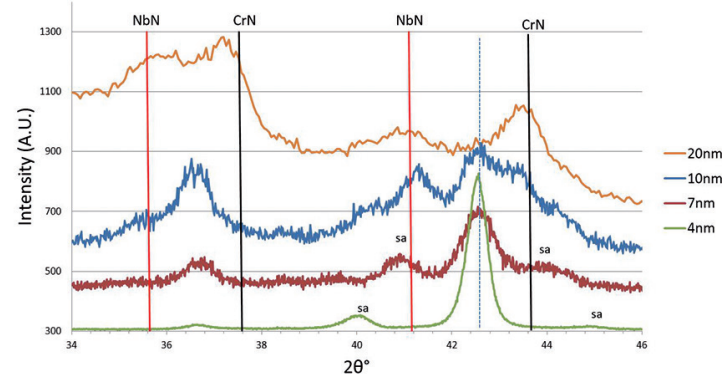

Figure 5: X-ray diffraction patterns of the four $\mathrm{NbN} / \mathrm{CrN}$ multilayer coatings with periodicities of $4 \mathrm{~nm}, 7.5 \mathrm{~nm}, 10 \mathrm{~nm}$ and $20 \mathrm{~nm}$. In the same image, the full lines in red and black indicate the positions corresponding to $\mathrm{NbN}$ and $\mathrm{CrN}$, ICDD \#38-1155 and ICDD \#11-65 cards, respectively in the (111) and (200). The dotted line, identified by "I", corresponds to the intermediate peaks of the $10 \mathrm{~nm}, 7.5$ $\mathrm{nm}$ and $4 \mathrm{~nm}$ periodicity multilayer coatings. "sa" are the satellite peaks around the central peak in the (200) position.

For the smallest periodicity studied in this work, the lattice parameters of the $\mathrm{NbN}$ and $\mathrm{CrN}$ sublayers change towards a common intermediate value (Figure 5).

The development of a (200) texture on $\mathrm{NbN} / \mathrm{CrN}$ coatings can be seen with periodicities smaller than $10 \mathrm{~nm}$, especially for $4 \mathrm{~nm}$ periodicity coating. Moreover, the diffraction patterns show a strong central peak, and a group of satellite peaks on its vicinities with gradually decreasing intensities. The central peak is located at $2 \theta=42.5^{\circ}$, and the first order satellite peaks are visible at both sides of the central peak, as predicted in the literature ${ }^{33-35}$.

Periodicity and average d-spacings for the coatings thinner than $10 \mathrm{~nm}$ were calculated based on the formulation described by Segmüller and Blakeslee ${ }^{36}$. Following this procedure, equation $2 \bar{d} \sin \theta=n \lambda$ identifies Bragg's central peak position related to the multilayer and $\Lambda=\left(N_{A}+N_{B}\right) \bar{d}$ determines the modulation period. In these equations, $N$ is the average number of planes and $\Lambda$ is the periodicity of two sublayers. The central peak position represents the average $d$-spacing between the sublayers, corresponding to the weighted average between the d-spacing of each sublayer component, and being calculated using equation 1 :

$$
\bar{d}=\frac{N_{N b N} d_{N b N}+N_{C r N} d_{C r N}}{N_{N b N}+N_{C r N}}
$$

The multilayer modulation period, calculated based on the position of satellite peaks is given by equation (2), where $m$ and $n$ are integers that represent the order of the satellite peaks chosen for $\Lambda$ calculation

$$
\wedge_{\text {sat }}=\frac{|m-n| \lambda}{2\left|\sin \left(\theta_{m}\right)-\sin \left(\theta_{n}\right)\right|}
$$

The identification of these parameters has been conducted with the help of the program SLERFWIN by G. Gladyszewski ${ }^{37}$. This software considers the Monte Carlo approach for modelling imperfect multilayers and is based on kinematic X-ray diffraction. The program was used to simulate X-ray patterns, which were latter compared with the diffraction patterns obtained experimentally. Figure 6 presents this comparison for the $\mathrm{NbN} / \mathrm{CrN}$ sample with a periodicity of $4 \mathrm{~nm}$ and $7.5 \mathrm{~nm}$, indicating a good match between simulated and experimental data.

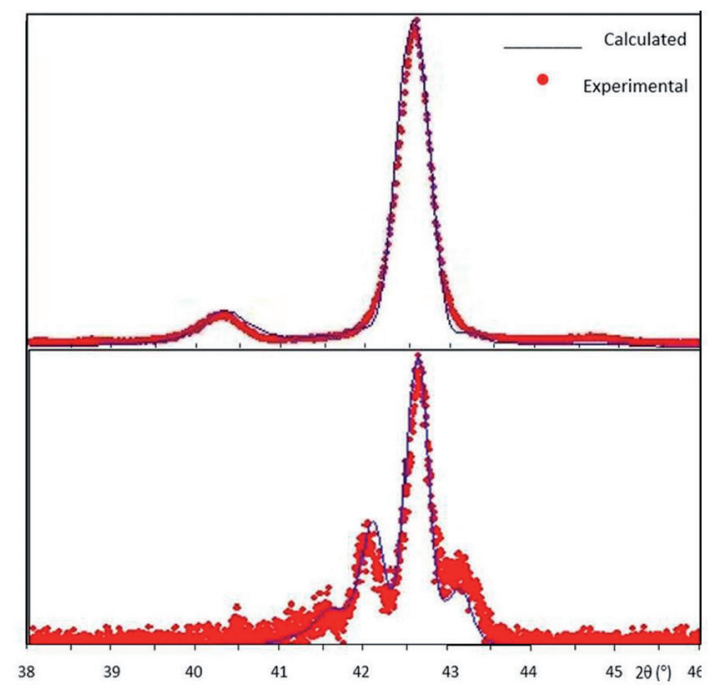

Figure 6: Experimental and calculated (using the SLERFWIN software) X-ray diffraction pattern in the (200) region, for $\mathrm{NbN} /$ $\mathrm{CrN}$ multilayer samples with a periodicity of $4 \mathrm{~nm}$ and $7.5 \mathrm{~nm}$.

Table 1 shows the structural parameters selected for the adjustment shown in Figure 6. Table 1 also presents the calculated periodicity and sub-layer thickness for the $4 \mathrm{~nm}$ and $7.5 \mathrm{~nm}$ coatings, as well as the values measured (for all specimens) by high-resolution transmission electron microscopy (HRTEM). Comparing the calculated and 
Table 1: Periodicity values and sublayers thickness as calculated by the SlerfWin Program for $\Lambda=4.0 \mathrm{~nm}$ and $7.5 \mathrm{~nm}$ ) and values measured by HRTEM for $\Lambda$ from 4 to $20 \mathrm{~nm}$.

\begin{tabular}{lcccccc}
\hline & \multicolumn{2}{c}{ X-Ray (calculated) } & \multicolumn{3}{c}{ HRTEM (measured) } \\
& $4 \mathrm{~nm}$ & $7.5 \mathrm{~nm}$ & $4 \mathrm{~nm}$ & $7.5 \mathrm{~nm}$ & $10 \mathrm{~nm}$ & $20 \mathrm{~nm}$ \\
\hline Periodicity & 3.6 & 7.2 & 4.0 & 7.7 & 10.5 & 20.7 \\
NbN sub-layer $(\mathrm{nm})$ & 1.7 & 3.2 & 1.9 & 3.6 & 4.7 & 9.6 \\
CrN sub-layer $(\mathrm{nm})$ & 1.9 & 4.0 & 2.1 & 4.1 & 5.8 & 11.1 \\
\hline
\end{tabular}

experimentally measured values, one can see differences smaller than $10 \%$, indicating a good fit.

The analysis of the microstructures by TEM indicates that all four coatings were formed by deposition of alternate $\mathrm{CrN}$ and $\mathrm{NbN}$ sublayers with decreasing periodicities of about $20.7 \mathrm{~nm}, 10.5 \mathrm{~nm}, 7.7 \mathrm{~nm}$ and $4.0 \mathrm{~nm}$. Due to the high total thickness of the coating, the inspection of the whole coating structure was conducted on different areas lying at different depths. It was observed that the sublayers thickness variation along the total coating was smaller than $7 \%$. Thus, the microstructure was found to be homogeneous along the whole coating thickness, confirming that the control of the rotating speed of the table is an effective tool to control the sublayer thickness. In comparison with sputtering-deposited $\mathrm{NbN} / \mathrm{CrN}$ coatings ${ }^{20,23}$, the coatings deposited in this work do not present an evident decrease in bi-layer period as the overall thickness increases, Figure 7. This decrease was observed by Lewis ${ }^{23}$ and was explained based on: (i) texture development and re-sputtering rate and (ii) target poisoning throughout the process. The consistency of the bi-layer periodicity along the coatings obtained in this work may be a result of (i) not only the characteristics of the cathodic arc process, in which the effect of target poisoning is not comparable with those of the sputtering processes, but also (ii) the use of lower bias voltages $(-20 \mathrm{~V}$ in comparison with -75 to $-150 \mathrm{~V})$.

In addition, a significant technological advantage results from this methodology, since all targets (Niobium and Chromium) work at the same time during the deposition process, optimizing the deposition rate and consequently reducing the coating manufacturing cost. High deposition rates, typical of the cathodic arc process $\left(\sim 3 \mu \mathrm{m} / \mathrm{h}^{13}\right.$ against $\sim 1 \mu \mathrm{m} / \mathrm{h}$ for sputtering ${ }^{23,29}$ ), were achieved. Moreover, the deposition parameters selected in this work allowed the deposition of $30 \mu \mathrm{m}$ thickness coatings, which are much larger than the reported similar multilayer systems below 7 $\mu \mathrm{m}^{20,23}$. The deposition of coatings with thickness above 30 $\mu \mathrm{m}$ may be mandatory in some applications; for example, in components for internal combustion engines, which are associated with operations over extended periods of time ${ }^{6,7}$.

Figure 7 also shows that $\mathrm{NbN}$ and $\mathrm{CrN}$ sublayers follow the irregularities of the surface of the substrate, as well as those due to the presence of metallic $\mathrm{Nb}$ and $\mathrm{Cr}$ macroparticles (droplets) deposited during the cathodic arc process. It is noted that these macroparticles affect neither the periodicity nor the individual layer thickness.

The columnar microstructure (with variable column widths between $50 \mathrm{~nm}$ and $100 \mathrm{~nm}$ ) overlaps the multilayer structure maintaining the same orientation by a mechanism of localized epitaxial growth. The width of these columns may increase or decrease along the coating thickness, according to the simultaneous growth rule .

Figure 8 shows a TEM image displaying the multilayers with their respective selected area diffraction patterns. This image indicates that both phases are face-centered cubic (fcc) and textured in the [002] direction.

A double spot can be observed in the area highlighted in Figure 8b, representing the two crystals of the $\mathrm{NbN}$ and CrN sublayers. They exhibit similar orientation with slightly different lattice parameters, indicating epitaxial growth of the sublayers.

Figure 9 shows a HRTEM image of the multilayer coating, at the earliest stages of the growth on top of the $\mathrm{Cr}$ interlayer. Although there is no parallelism between atomic planes of the $\mathrm{Cr}$ interlayer and the first deposited $\mathrm{NbN}$ sublayer, parallelism can be observed between the atomic
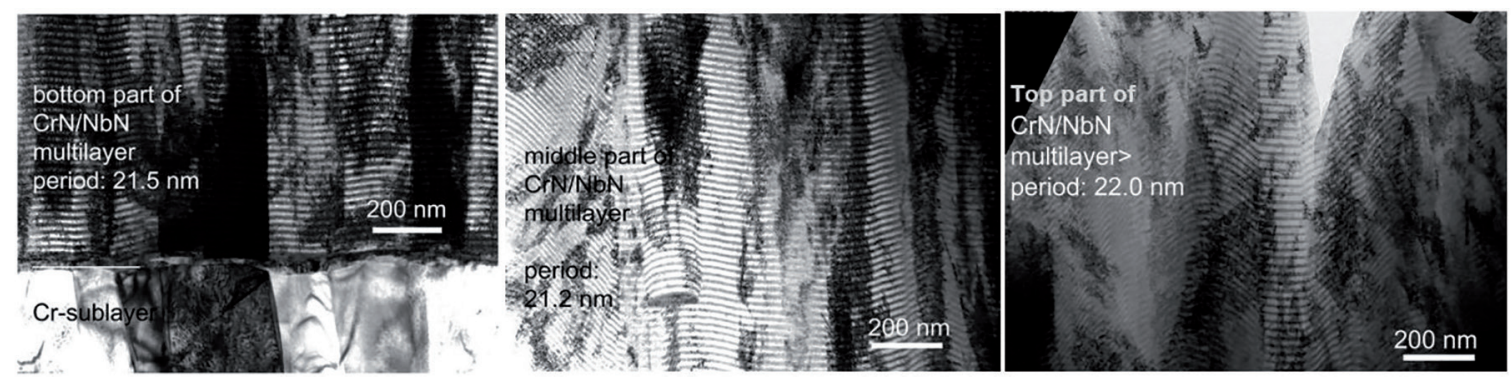

Figure 7: Bright-field micrographs of the cross-section of the $\mathrm{NbN} / \mathrm{CrN}$ multilayer coating with periodicity of $\sim 20 \mathrm{~nm}$ taken (a) near the interface; (b) at the middle of the coating and (c) near the surface. 


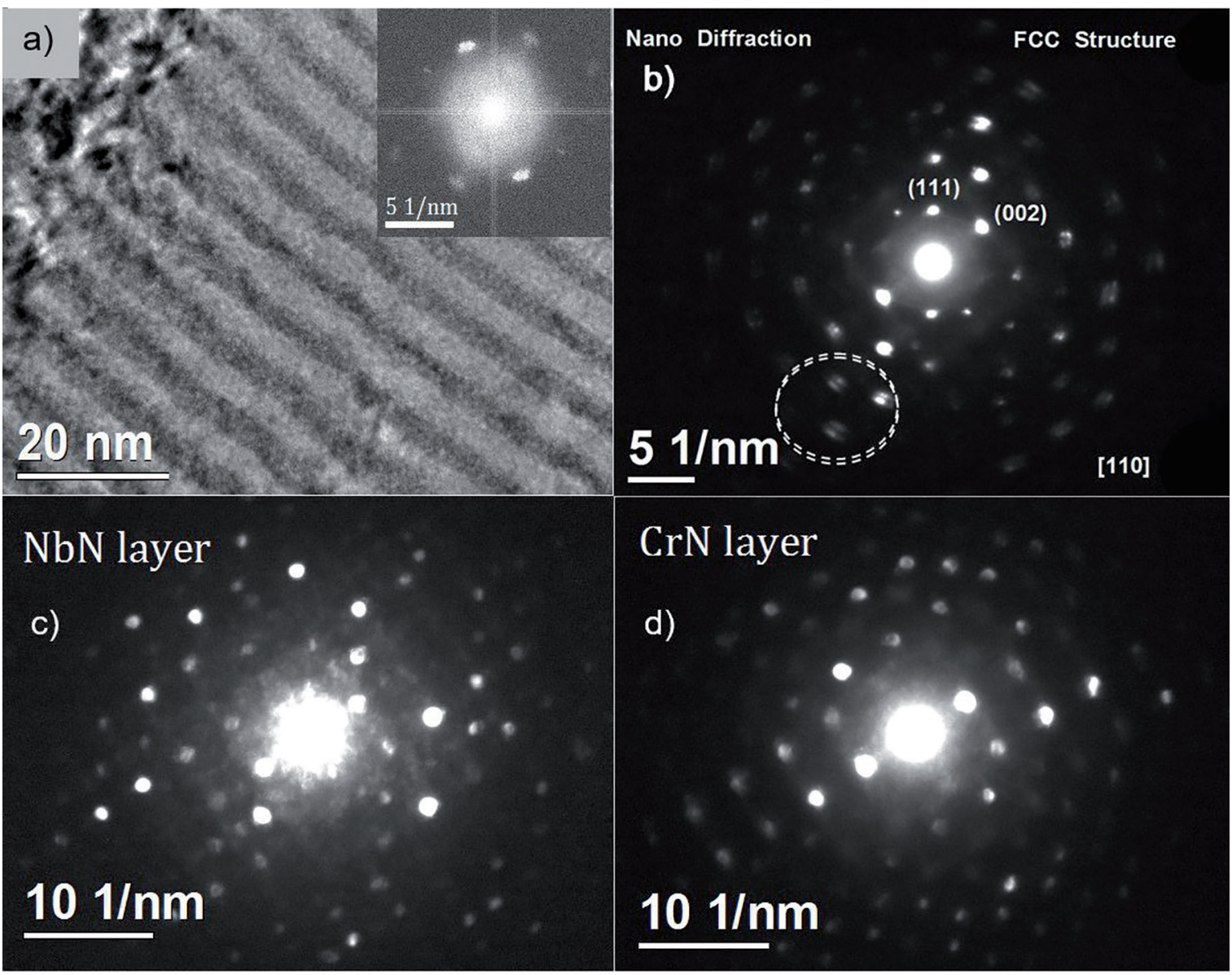

Figure 8: TEM image of a $\sim 10 \mathrm{~nm}$ multilayer coating, with its respective Electron diffraction pattern. (a) The micrograph shows the region used for acquiring the diffraction patterns. (b) Electron diffraction pattern obtained from an area (diameter $50 \mathrm{~nm}$ ) enclosing both $\mathrm{NbN}$ and $\mathrm{CrN}$ layers and diffraction spots from individual $\mathrm{NbN}$ and $\mathrm{CrN}$ layers (c and d, respectively).

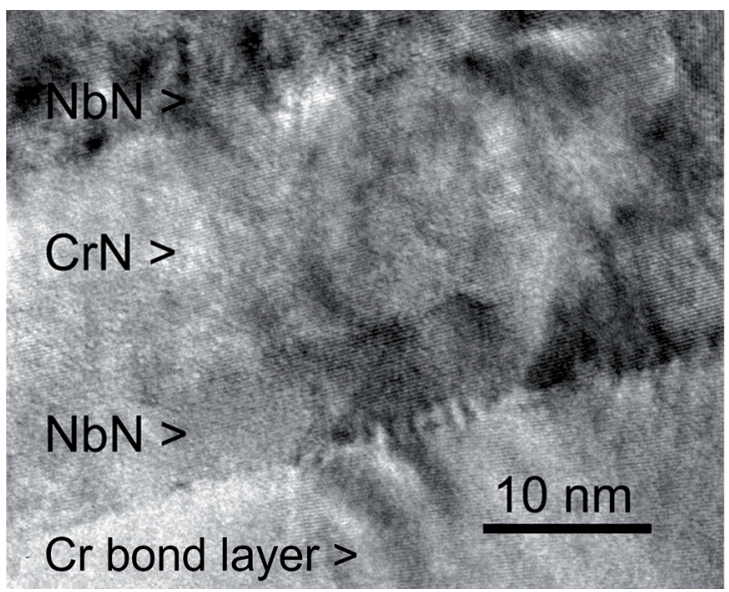

Figure 9: HRTEM image of the multilayer coating, at the earliest stages of growth on top of the $\mathrm{Cr}$ interlayer. $\mathrm{NbN} / \mathrm{CrN}$ coating with periodicity of $20 \mathrm{~nm}$.

planes of the subsequent $\mathrm{CrN}$ and $\mathrm{NbN}$ sublayers and even localized epitaxy.

The $\mathrm{NbN}$ and $\mathrm{CrN}$ layers could be related to coherence stresses and hardness, which increases as the periodicity decreases. Although the presence of metallic $\mathrm{Cr}$ and $\mathrm{Nb}$ macroparticles caused a disorder in the layer regularity, it was possible to detect the formation of superlattice, satellite peaks on coatings of 7.5 and $4 \mathrm{~nm}$.

\subsection{Microhardness and periodicity}

Nanohardness measurements were performed along the entire coating thickness, from surface to base material. Figure 10 presents the plotted nanohardness profile along the entire $30 \mu \mathrm{m}$ thickness of the $20 \mathrm{~nm}$ periodicity $\mathrm{NbN} / \mathrm{CrN}$. These measurements were performed in order to illustrate that no significant variation in hardness was detected along the thickness of the $\mathrm{NbN} / \mathrm{CrN}$ multilayer coatings. Local variations in hardness values can be attributed to the presence of macroparticles on the coating.

Since Figure 10 indicates that no hardness variation occurs along the thickness of the $\mathrm{NbN} / \mathrm{CrN}$ multilayer coatings, microhardness measurements were performed on polished cross sections of multilayer coatings with different periodicities, in order to investigate the effect of the multilayer periodicity on the overall hardness of the coating. The results 


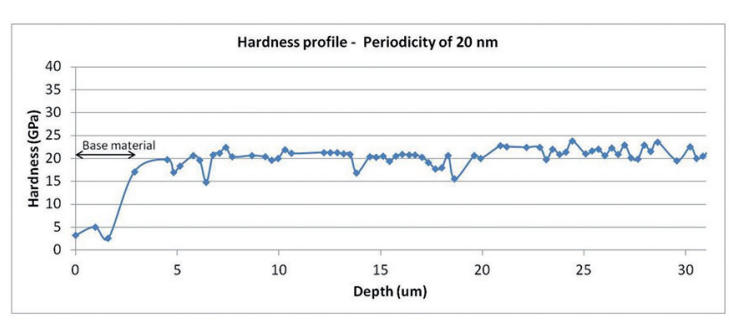

Figure 10: Nanohardness profile of $\mathrm{NbN} / \mathrm{CrN}$ multilayer coating $(\Lambda=20 \mathrm{~nm})$ as a function of coating thickness.

are presented in Figure 11. This plot includes values obtained with specimens with other periodicities than the four detailed in this work, but produced following the same procedure. Figure 11 indicates that hardness increases as the periodicity decreases from $20 \mathrm{~nm}$ to $4 \mathrm{~nm}$. This result is in agreement with previous works ${ }^{41-43}$, which reported hardness values 2-3 times greater for polycrystalline nitride multilayer coating ( TiN/NbN) than for those of homogenous TiN and $\mathrm{NbN}$.

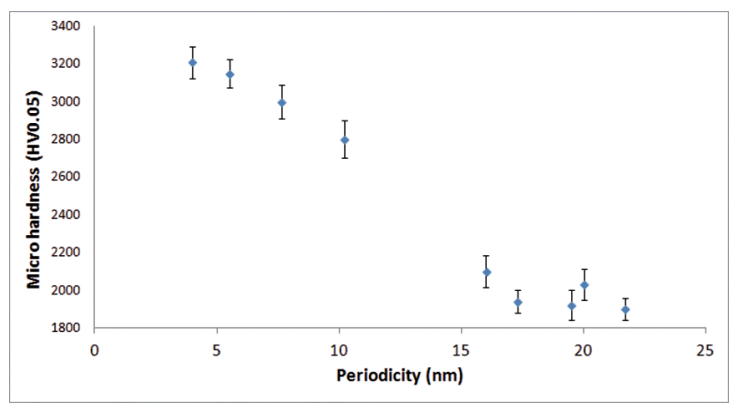

Figure 11: Hardness variation as a function of $\mathrm{NbN} / \mathrm{CrN}$ multilayer coating bilayer periodicity.

In the 1970's, Koehler suggested that a multilayer coating composed of two different materials with the same crystalline structure would result in a material with very high hardness and toughness, since the interfaces would act as barriers for dislocation movement ${ }^{41}$. Some decades later, Sproul et $a l .^{42}$ stated that several explanations have been proposed to explain the hardness increase, including not only the dislocation barrier due to the interface mismatch ${ }^{43}$ but also the Hall Petch effect ${ }^{44}$. Additionally, coherent strain and the effect of different modulus of elasticity between sub-layers have been suggested as mechanisms that may contribute for hardness increase. More specifically, Hultman et al. ${ }^{45}$ investigated the TiN/NbN system and concluded that plastic deformation and dislocation movement are limited within each sublayer during a scratch test. The hardening effect was once again attributed to the dislocations confinement between the sub-layer interfaces.

Following the concepts presented previously, the hardening effect in multilayer coatings with periodicity around $10 \mathrm{~nm}$ and below can be explained by the presence of several sublayers and by the different lattice parameters of each sublayer. The $\mathrm{NbN}$ lattice is around 4\% larger than the $\mathrm{CrN}$ lattice. The presence of the sublayers forces the crystallographic planes to align, thus reducing the difference between lattice parameters of each sublayer, which is adjusted by elastic stresses. These stresses difficult dislocation movement across the interface. In multilayer coatings with periodicity values greater than $10 \mathrm{~nm}$, the stresses are increasingly relieved within the sublayers, due to the presence of interfacial misfit dislocations and semi-coherent interfaces ${ }^{9,46}$.

\section{Conclusions}

$\mathrm{NbN} / \mathrm{CrN}$ nanostructured multilayers were manufactured by PVD (ARC process). The X-ray analysis combined with computer modeling, allowed the determination of the multilayers periodicity and the d-spacing for $\mathrm{NbN}$ and $\mathrm{CrN}$ sub-layers. Furthermore, columnar structures with the same crystallographic orientation were formed.

The homogeneity of periodicity throughout the coatings confirms that the deposition rate of $\mathrm{CrN}$ and $\mathrm{NbN}$ is stable and that the substrate rotation is the main variable in this control. A technological advantage results from this methodology, since both targets (niobium and chromium) work at the same time, improving the deposition rate and reducing the manufacturing cost.

As the coating thickness increases, the sublayer surface becomes more irregular, due to the accumulation of defects and macroparticles. Thus, for engineering applications, surface finishing after coating deposition is required in order to control the roughness.

The modulation periods for those multilayers as determined by X-rays were similar to those measured by Transmission Electronic Microscopy (TEM). When combining the TEM with high angle X-rays analysis, it can be concluded that this last technique is a useful and simple tool to measure the periodicity of nanostructured multilayer coatings, even in coatings prepared by cathodic arc.

The hardness increase observed for the $\mathrm{NbN} / \mathrm{CrN}$ system is in agreement with the literature, showing that despite the typical discontinuities of the cathodic arc processes, it was possible to take advantage of the combination of nanostructured multilayers.

\section{Acknowledgements}

The authors acknowledge the financial support from the São Paulo State Research Foundation, FAPESP, processes n. 2012/50890-0, and from National Research Foundation - CNPQ processes n. 481918/2010-8 and $486104 / 2012-5$, to Dr. Carlos Tavares (University of Minho) for his support on X-ray diffraction modelling and analysis and to LNNano - Brazilian Nanotechnology 
National Laboratory at CNPEM - Brazilian National Center of Research in Energy and Materials for the Electron Microscopy Measurements.

\section{References}

1. Aubert A, Gillet R, Gaucher A, Terrat JP. Hard chrome coatings deposited by physical vapour deposition. Thin Solid Films. 1983;108(2):165-172.

2. Mayrhofer PH, Willmann H, Mitterer C. Oxidation kinetics of sputtered $\mathrm{Cr}-\mathrm{N}$ hard coatings. Surface and Coatings Technology. 2001;146-147:222-228.

3. Kashiwagi K, Kobayashi K, Masuyama A, Murayama Y. Chromium nitride films synthesized by radio-frequency reactive ion plating. Journal of Vacuum Science \& Technology A. 1986;4(2):210-214.

4. Ballhause P, Hensel B, Rost A, Schüssler H. CrNx - a hard coating for corrosion and wear resistance. Materials Science and Engineering: A. 1993;163(2):193-196.

5. Friedrich C, Berg G, Broszeit E, Rick F, Holland J. PVD Cr $r_{x} \mathrm{~N}$ coatings for tribological application on piston rings. Surface and Coatings Technology. 1997;97(1-3):661-668.

6. Ferrarese A, Banfield R, Tomanik E. High value PVD top ring for high speed diesel engines. SAE Technical Paper 200801-0793. Warrendale: SAE International; 2008.

7. Warkentin T, Banfield R, Nocera E. New ring pack for $H D D$ engines. SAE Technical Paper 2007-01-2846. Warrendale: SAE International; 2008.

8. Cansever N. Properties of niobium nitride coatings deposited by cathodic arc physical vapor deposition. Thin Solid Films. 2007;515(7-8):3670-3674

9. Münz WD, Lewis DB, Hovsepian PE, Schönjahn C, Ehiasarian A, Smith IJ. Industrial scale manufactured superlattice hard PVD coatings. Surface Engineering. 2001;17(1):15-27.

10. Ehiasarian AP, Wen JG, Petrov I. Interface microstructure engineering by high power impulse magnetron sputtering for the enhancement of adhesion. Journal of Applied Physics. 2007;101(5):054301

11. Reinhard C, Ehiasarian AP, Hovsepian PE. CrN/NbN superlattice structured coatings with enhanced corrosion resistance achieved by high power impulse magnetron sputtering interface pre-treatment. Thin Solid Films. 2007:515(7-8):3685-3692.

12. Münz WD, Donohue LA, Hovsepian PE. Properties of various large-scale fabricated TiAlN and CrN-based superlattice coatings grown by combined cathodic arc-unbalanced magnetron sputter deposition. Surface and Coatings Technology. 2000;125(1-3):269-277.

13. Bemporad E, Pecchio C, Rossi S, Carassiti F. Characterization and wear properties of industrially produced nanoscaled $\mathrm{CrN} /$ $\mathrm{NbN}$ multilayer coating. Surface and Coatings Technology. 2004;188-189:319-330.

14. Tomlinson M, Lyon SB, Hovsepian PE, Munz WD. Corrosion performance of $\mathrm{CrN} / \mathrm{NbN}$ superlattice coatings deposited by the combined cathodic arc/unbalanced magnetron technique. Vacuum. 1999;53(1-2):117-121.
15. Pecchio C, Bemporad E, De Felicis D, De Rossi S, Carassiti F. Production of $\mathrm{CrN} / \mathrm{NbN}$ superlattice coatings by cathode switching reactive cathodic arc evaporation, International conference on computer methods and experimental measurements for surface treatment effect. In: de Hosson JTM, Brobbia CA, Nishida SI. Surface Treatment VI Computer Methods and Experimental Measurements for Surface Treatment Effects. Southampton: WIT Press; 2003.

16. Setoyama M, Nakayama A, Tanaka M, Kitagawa N, Nomura T. Formation of cubic-A1N in TiN/A1N superlattice. Surface and Coatings Technology. 1996;86-87(Pt 1):225-230

17. Hultman L, Engström C, Odén M. Mechanical and thermal stability of TiN/NbN superlattice of thin films. Surface and Coatings Technology. 2000;133-134:227-233.

18. Wadsworth I, Smith IJ, Donohue LA, Münz WD. Thermal stability and oxidation resistance of TiAlN/CrN multilayer coatings. Surface and Coatings Technology. 1997;9495:315-321.

19. Hovsepian PE, Münz WD. Advanced application tailored PVD coatings utilizing nanoscaled multilayer/superlattice structures. In: Proceedings of the $45^{\text {th }}$ Annual Technical Conference of the Society of Vacuum Coaters; 2002 Apr 13-18; Lake Buena Vista, FL, USA

20. Hovsepian PE, Lewis DB, Münz WD, Rouzaud A, Juliet P. Chromium nitride/niobium nitride superlattice coatings deposited by combined cathodic-arc/unbalanced magnetron technique. Surface and Coatings Technology. 1999,116119:727-734.

21. Hovsepian PE, Lewis DB, Münz WD, Lyon SB, Tomlinson $M$. Combined cathodic arc/unbalanced magnetron grown $\mathrm{CrN} / \mathrm{NbN}$ superlattice coatings for corrosion resistant applications. Surface and Coatings Technology. 1999;120121:535-541.

22. Hovsepian PE, Lewis DB, Luo Q, Farinotti A. Corrosion resistance of $\mathrm{CrN} / \mathrm{NbN}$ superlattice coatings grown by various physical vapour deposition techniques. Thin Solid Films. 2005;488(1-2):1-8.

23. Lewis DB, Reitz D, Wüstefeld C, Ohser-Wiedemann R, Oette H, Ehiasarian A, et al. Chromium nitride/niobium nitride nano-scale multilayer coatings deposited at low temperature by the combined cathodic arc/unbalanced magnetron technique. Thin Solids Films. 2006;503(12):133-142.

24. Wang HW, Stack MM, Lyons SB, Hovsepian P, Münz WD. The corrosion behaviour of macroparticle defects in arc bond-sputtered $\mathrm{CrN} / \mathrm{NbN}$ superlattice coatings. Surface and Coatings Technology. 2000;126(2-3):279-287.

25. Wang HW, Stack MM, Lyon SB, Hovsepian PE, Münz WD. Wear associated with growth defects in combined cathodic arc/unbalanced magnetron sputtered $\mathrm{CrN} / \mathrm{NbN}$ superlattice coatings during erosion in alkaline slurry. Surface and Coatings Technology. 2000;135(1):82-90.

26. Ceschini L, Lanzoni E, Martini C, Prandstraller D, Sambogna G. Comparison of dry sliding friction and wear of Ti6Al4V alloy treated by plasma electrolytic oxidation and PVD coating. Wear. 2008;264(1-2):86-95. 
27. Martini C, Ceschini L. A comparative study of the tribological behaviour of PVD coatings on the Ti-6Al-4V alloy. Tribology International. 2011;44(3):297-308.

28. Pilone D, Bernabai U. Effect of substrate on wear performance of multilayer hard coating. Surface Engineering. 2008;24(3):193-197.

29. Savisalo T, Lewis DB, Luo Q, Bolton M, Hovsepian P. Structure of duplex $\mathrm{CrN} / \mathrm{NbN}$ coatings and their performance against corrosion and wear. Surface and Coatings Technology. 2008;202(9):1661-1667.

30. Araujo JA, Souza RM, Araujo GM, Tschiptschin AP. Effect of periodicity on hardness and scratch resistance of $\mathrm{CrN} /$ $\mathrm{NbN}$ nanoscale multilayer coating deposited by cathodic arc technique. Wear. 2015;330-331:469-477.

31. Zuo JM, Gao M, Tao J, Li BQ, Twesten R, Petrov I. Coherent nano-area electron diffraction. Microscopy Research and Technique. 2004;64(5-6):347-355.

32. Vaz F, Ferreira J, Ribeiro E, Rebouta L, Lanceros-Méndez $\mathrm{S}$, Mendes JA, et al. Influence of nitrogen content on the structural, mechanical and electrical properties of TiN thin films. Surface and Coatings Technology. 2005;191(23):317-323.

33. Thomas O, Gergaud P, Labat S, Barrallier L, Charai A, Alfonso C, et al. Residual Stresses in Metallic Multilayers. Journal de Physique IV France. 1996;6(C7):125-134.

34. Tavares CJ, Rebouta L, Rivière JP, Pacaud J, Garemb H, Pischowc K, et al. Microstructure of superhard (Ti,Al)N/ Mo multilayers. Thin Solid Films. 2001;398-399:397-404.

35. Tavares CJ, Vidrago C, Rebouta L, Rivière JP, Le Bourhis E, Denanot MF. Optimization and thermal stability of TiAlN/Mo multilayers. Surface and Coatings Technology. 2005;200(1-4):288-292.
36. Segmüller A, Blakeslee AE. X-ray diffraction from onedimensional superlattices in $\mathrm{GaAs}_{1-\mathrm{x}} \mathrm{P}_{\mathrm{x}}$ crystals. Journal of Applied Crystallography. 1973;6(1):19-25.

37. Gladyszewski G. High resolution studies of interfacial effects by small and large angle X-ray diffraction. Thin Solid Films. 1991;204(2):473-484.

38. Chu X, Barnett SA. Model of superlattice yield stress and hardness enhancements. Journal of Applied Physics. 1995;77(9):4403-4411.

39. Chu X, Wong MS, Sproul WD, Rohde SL, Barnett SA. Deposition and properties of polycrystalline TiN/NbN superlattice coatings. Journal of Vacuum Science and Technology A. 1992;10(4):1604-1609.

40. Shinn M, Hulman L, Barnett SA. Growth, structure and microhardness of epitaxial TiN/NbN superlattices: Journal of Materials Research. 1992;7(4):901-911.

41. Koehler JS. Attempt to Design a Strong Solid, Physical Review B.1970;2(2):547-551.

42. Sproul WD, Yashar PC. Nanometer scale multilayered hard coatings. Vacuum. 1999;55(3-4):179-190.

43. Chu X, Barnett SA. Model of superlattice yield stress and hardness enhancements. Journal of Applied Physics. 1995;77(1):4403-4411.

44. Anderson PM, Li C. Hall-Petch relations for multilayered materials. Nanostructured Materials. 1995;5(3):349-362.

45. Hultman L, Engstrom UC, Oden M, Birch J, Johansson M, Karlsson L. Review of the thermal and mechanical stability of TiN based thin films. Zeitschrift fur Metallku nde.1999;90(10):803-813.

46. Movchan BA, Demchishin AV. Study of the structure and properties of thick vacuum condensates of nickel, titanium, tungsten, aluminum oxide and zirconium oxide. Physics of Metals and Metallography. 1969;28(1996):83-90. 